\title{
Increased NO bioavailability in aging male rats by genistein and exercise training: using 4, 5-diaminofluorescein diacetate Sukanya Eksakulkla1 ${ }^{1}$, Daroonwan Suksom ${ }^{2}$, Prasong Siriviriyakul ${ }^{3}$ and Suthiluk Patumraj*3
}

Address: ${ }^{1}$ Inter-department of Physiology, Graduate School, Chulalongkorn University, Bangkok 10330, Thailand, ${ }^{2}$ School of Sports Science, Chulalongkorn University, Bangkok 10330, Thailand and ${ }^{3}$ Department of Physiology, Faculty of Medicine, Chulalongkorn University, Bangkok 10330, Thailand

Email: Sukanya Eksakulkla - sukunyaj21@yahoo.com; Daroonwan Suksom - daroonwanc@hotmail.com; Prasong Siriviriyakul - medspr@hotmail.com; Suthiluk Patumraj* - suthilukp@yahoo.com

* Corresponding author

Published: 7 September 2009

Reproductive Biology and Endocrinology 2009, 7:93 doi:10.1/86/1477-7827-7-93

This article is available from: http://www.rbej.com/content/7///93

(c) 2009 Eksakulkla et al; licensee BioMed Central Ltd.

This is an Open Access article distributed under the terms of the Creative Commons Attribution License (http://creativecommons.org/licenses/by/2.0), which permits unrestricted use, distribution, and reproduction in any medium, provided the original work is properly cited.
Received: 14 July 2009

Accepted: 7 September 2009

\begin{abstract}
Background: Several kinds of anti-oxidants have drawn a lot of intension for their benefits on vascular protection. In addition, it has been demonstrated that exercise training could improve endothelial function by up-regulating endothelial nitric oxide synthase (eNOS) protein. Therefore, the present study aims to investigate the effects of genistein, a potent phyto-antioxidant, and exercise training on age-induced endothelial dysfunction in relation to NO bioavailability using in situ NO-sensitive fluorescent dye detection.
\end{abstract}

Methods: Male Wistar rats (20-22-month old) were divided into four groups: aged rats treated with corn oil, (Aged+Veh, $n=5$ ), aged rats treated with genistein (Aged +Gen, $n=5,(0.25 \mathrm{mg} / \mathrm{kg}$ $B W /$ day, s.c.)), aged rats with and without exercise training (Aged $+E x, n=5$, swimming $40 \mathrm{~min} /$ day, 5 days/week for 8 weeks) (Aged+Without-Ex, $n=5)$. Cremaster arterioles (I5-35 micrometer) were visualized by fluorescein isothiocyanate labeled dextran $(5 \mathrm{microgram} / \mathrm{ml})$. The vascular response to acetylcholine (Ach; $10-5 \mathrm{M}, 5 \mathrm{ml} / 5 \mathrm{~min}$ ) was accessed after I-min norepinephrine preconstriction ( 10 micro molar). To determine NO bioavailability, the Krebs-Ringer buffer with 4, 5-diaminofluorescein-diacetate (3 micro molar DAF-2DA), and 10 micro- molar Ach saturated with $95 \% \mathrm{~N}_{2}$ and $5 \% \mathrm{CO}_{2}$ were used. Changes of DAF-2T-intensities along the cremaster arterioles were analyzed by the Image Pro-Plus Software (Media Cybernatics, Inc, USA). Liver malondialdehyde (MDA) level was measured by thiobarbituric acid reaction and used as an indicator for oxidative stress.

Results: The results showed that means arterial blood pressure for both Aged+Gen and Aged+Ex groups were significantly reduced when compared to the Aged groups, Aged+Veh and Aged+Without-Ex $(P<0.05)$. Among the treated groups, Ach-induced vasodilatation were significantly increased $(P<0.05)$ and was associated with increased NO-associated fluorescent intensities $(P<0.05)$. On the other hand, MDA levels were significantly reduced $(P<0.05)$ when Aged+Veh was compared to Aged+Without-Ex.

Conclusion: These findings showed that genistein and exercise training could improve ageinduced endothelial dysfunction and is related to the increased NO bioavailability. 


\section{Background}

Aging is a dependent risk factor for the development of vascular diseases in association with a progressive endothelial dysfunction $[1,1]$. It is believed that reduced basal endothelium-derived vasodilators, such as nitric oxide (NO), contribute to the age-related increase in peripheral vascular resistance and systemic hypertension $[3,3]$. From epidemiological and experimental studies, they have shown that an increased superoxide $\left(\mathrm{O}_{2}^{-}\right)$production with advancing age causes oxidative stress and leads to the development of endothelial dysfunction [510]. Superoxide $\left(\mathrm{O}_{2}^{-}\right)$is a free radical that can rapidly scavenge NO directly, and this age-induced oxidative stress may contribute to the reduction of NO bioavailability [11]. Therefore, several studies have investigated the roles of phyto-substances with anti-oxidative properties and their benefits as vasculoprotective agents. As of note, especially in East Asian population, high plasma concentration of genistein, a soy product, contributes to a strikingly low incidence of atherosclerosis and coronary heart disease [12-14]. It has been reported that genistein, a phytoestrogen acting as estrogenic cardioprotector [13], could enhance coronary vasoreactivity and inhibit the oxidative stress [15-17]. Genistein, an anti-oxidant, could produce acute NO-dependent vasodilatation in the forearm vasculature of men and women with potency similar to that of $17 \beta$-estradiol [18-22]. Moreover, aerobic exercise training appears to reverse old age-associated reductions in endothelium-dependent vasodilatation in humans $[2,23,24]$. Therefore, we evaluate the effects of genistein and exercise training on protecting endothelial cells against age-induced oxidative stress by using a fluorescent indicator-diaminofluorescein (DAFs). This technique allowed us to examine the in situ release of NO from cremasteric endothelial cells after acetylcholine activation.

\section{Methods}

\section{Animal preparation}

The present study was conducted in accordance with the guidelines for animal experimentation of the National Research Council of Thailand and approved by Ethical Committee, Faculty of Medicine, Chulalongkorn University.

Male Wistar rats aged 20-22 months $(\mathrm{n}=20)$ were used in this study. The animals were obtained from National Laboratory Animal Center, Salaya Campus, Nakhonprathom, Thailand, and housed in the animal laboratory center at the Faculty of Medicine, Chulalongkorn University until they were used. The rats were fed with the standard chow and drank tap water ad libitum. The room was temperature controlled at $25^{\circ} \mathrm{C}$, and has a 12:12-light-dark cycle. The old rats were randomly divided into four groups: aged rats treated with corn oil (Aged+Veh $(\mathrm{n}=5)$; Sigma-Aldrich Co., USA), aged rats treated with genistein (Aged+Gen, (n
= 5); Sigma-Aldrich Co., USA, $0.25 \mathrm{mg} / \mathrm{kg}$ BW/day, s.c.) [19], and aged rats with exercise training (Aged+Ex ( $\mathrm{n}=$ $5)$ ). Aged+Gen rats received genistein injection every day for 8 weeks. For the Aged+Ex group, swimming exercise training protocol was conducted in 2 phases, adaptation and training. The adaptation phase consisted of the first 5 days of training. On the first day, the animals exercised in a round plastic tank (diameter $=38.5 \mathrm{~cm}$, depth $=35 \mathrm{~cm}$, water temperature about $34-36^{\circ} \mathrm{C}$ ) for 10 minutes. The exercise period was extended by 10 minutes every day until the rats could swim for 40 minutes. The training phase consisted of swimming $40 \mathrm{~min} /$ day, 5 days/week for a total of 8 weeks [25]. Swimming exercise was selected because it did not cause foot injuries, and is physically less traumatic for the animal. In the Aged+Without-Ex group $(n=5)$, the rats were immersed in water as to make them wet for $30 \mathrm{~min} /$ day, 5 day/week for a total of 8 weeks [25]. As of note, in this study, male Wistar rats aged 4-6 months $(\mathrm{n}=5)$ were used as controls.

On week 8 , all rats were anesthetized intraperitoneally with pentobarbital sodium ( $50 \mathrm{mg} / \mathrm{kg} \mathrm{BW})$. After tracheotomy, a polyethylene tube was inserted into the carotid artery to measure the arterial blood pressure. The jugular vein was cannulated for fluorescence tracer. In vivo microcirculatory observations were performed in the cremaster muscle according to the methods described by Gavins et al. (2004) [26]. The cremaster muscle was carefully spread over a chamber that was continuously perfused with $37^{\circ} \mathrm{C}$ Krebs-Ringer buffer (composition in $\mathrm{mmol} / \mathrm{L}$ : 135.7 $\mathrm{NaCl}, 4.7 \mathrm{KCl}, 2.52 \quad \mathrm{CaCl}_{2}, 1.18 \mathrm{KH}_{2} \mathrm{PO}_{4}, 1.64$ $\mathrm{MgSO}_{4} .7 \mathrm{H}_{2} \mathrm{O}$, and $7.14 \mathrm{NaHCO}_{3}$ ) at pH 7.4 and equilibrated with $5 \% \mathrm{CO}_{2}-95 \% \mathrm{~N}_{2}$. The rate of perfusion was kept constant at $2 \mathrm{ml} / \mathrm{min}$ [26].

\section{Arteriolar response to acetylcholine and sodium nitroprusside}

The second or third-order cremasteric arterioles (15 to 35 $\mu \mathrm{m}$ in diameter) were labeled with $5 \%$ fluorescein isothiocyanate-labeled dextran (FITC-dextran 250, $5 \mu \mathrm{g} / \mathrm{ml}$; Sigma-Aldrich Co., USA) which was injected into the jugular vein. After the arterioles were pre-constricted with norepinephrine $\left(10^{-5} \mathrm{M} \mathrm{NE} ; 0.1 \mathrm{ml} / \mathrm{min}\right)$, it was later dilated by applying acetylcholine $\left(10^{-5} \mathrm{M}\right.$ Ach; $5 \mathrm{ml} / 5$ min) topically. The changes of vascular diameters were recorded real time throughout the experiment with a black and white video monitor (Sony, GM-1411 QM) and an epi-illumination fluorescence videomicroscopy system (Optiphot 2, Nikon, Japan) equipped with a $100 \mathrm{~W}$ mercury lamp, real time CCD camera (Hamamatsu C2400, Japan), a video recorder (VC-S5, Sharp, Japan) with a video timer (VTG-33, For-A, Japan) and a $20 \times$ objective lens (CF Plan Fluor, Nikon, Japan). Cremasteric arteriolar diameter was measured by using the software (Image-Pro Plus; Media Cybernatics, Inc, USA). The arteriolar diame- 
ter was calculated by averaging three measurements obtained from three different video frames using the same reference point as a marker for measuring each vessel in each frame. Arteriolar diameters were measured five minutes after Ach administration. Vasodilatation responses were expressed as the percentage of maximal relaxation after norepinephrine $\left(\mathrm{NE} ; 10^{-5} \mathrm{M}\right)$ preconstriction.

Under the same protocol, after the arteriole was selected, it was washed by Krebs-Ringer solution ( $\mathrm{pH} 7.4)$ until its diameter was returned to normal. The SNP $\left(10^{-5} \mathrm{M} ; 5 \mathrm{ml} /\right.$ $5 \mathrm{~min}$ ), an endothelium-independent vasodilator, was applied topically on the arterioles after it was pre-constricted with NE. Vasodilatation responses were expressed as the percentage of maximal relaxation after norepinephrine $\left(\mathrm{NE} ; 10^{-5} \mathrm{M}\right)$ preconstriction.

\section{Direct detection of NO production}

On the experiment day, the cremaster microcirculation was observed under intravital fluorescent video microscope with a $20 \times$ objective lens and a $10 \times$ eyepieces. To visualize microvascular distribution of NO, diaminofluorescein-2 (DAF-2DA, Cayman Chemical Company, Michigan, USA), a NO-sensitive fluoroprobe, was used. After the cremaster was superfused with Krebs- Ringer buffered solution containing $3 \mu \mathrm{M}$ DAF-2DA and $10^{-5} \mathrm{M}$ Ach, NO levels from Ach-activated endothelial cells were analyzed at two different time points, $0 \mathrm{~min}\left(\mathrm{I}_{0} \mathrm{~min}\right)$ and $20 \mathrm{mins}$ $\left(\mathrm{I}_{20 \mathrm{~min}}\right)[27,27]$.

DAF-2DA can readily enter the cells and hydrolyzed by cytosolic esterase to DAF-2, which is trapped inside the cells. In the presence of NO, the relatively non-fluorescent DAF-2 is converted into a highly green fluorescent triazole form, DAF-2T (shown in diagram below). Thus the increases in DAF-2T fluorescent intensity represent of the cremasteric microcirculation would indicate an elevation of nitric oxide having by an excitation and emission wavelengths of 488 and $538 \mathrm{~nm}$, respectively $[27,27,29]$.

$$
\underset{\text { Non-fluorescent }}{\mathrm{DAF}}-2 \mathrm{DA} \stackrel{\text { Esterase }}{\longrightarrow} \mathrm{DAF}-2+\mathrm{NO} \rightarrow \underset{\text { Triazolofluorescein }}{\mathrm{DAF}-2 \mathrm{~T}}
$$

The cremasteric microcirculation was epi-illuminated having an excitation wavelength of $488 \mathrm{~nm}$ and emission wavelength of $538 \mathrm{~nm}$. The microscopic field containing arterioles (15 to $35 \mu \mathrm{m}$ in diameter) sharing the same focusing plane were selected and recorded for further analysis using Image Pro-Plus V. 5 software. (Media Cybernatics, Inc, USA). From fourteen small working window frames $\left(7 \times 3 \mu \mathrm{m}^{2}\right.$ each window $)$, the fluorescent intensity of each arteriolar vascular wall was averaged (Figure 1). Assuming that DAF-2T intensity is linearly related to the intracellular NO content, the difference in fluorescent intensity between $\mathrm{I}_{0 \text { min }}$ and $\mathrm{I}_{20 \text { min }}$ was calcu-

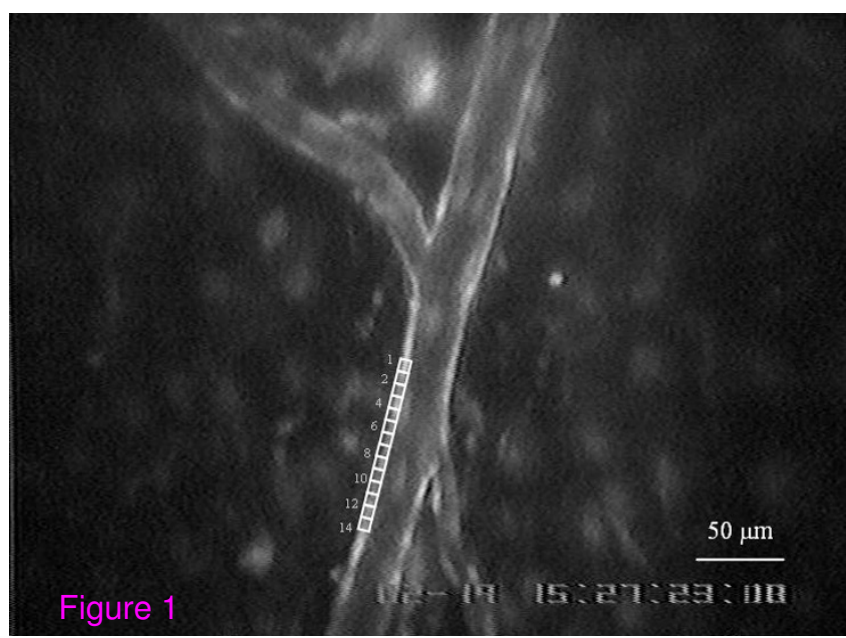

Figure I

This figure showed a videoimage of NO-associated fluorescent intensity taken from cremasteric arteriole of a young rat by using $20 \times$-objective lenses. From 14 frames of working windows, the Histogram Menu in Image Program Software was used to define the mean value of fluorescent intensity of each window, and then the averaged intensity was calculated for all 14 small working window frames $\left(7 \times 3 \mu \mathrm{m}^{2}\right.$ each window). The intensity difference $\left(I_{\text {diff }}\right)$ between the averaged intensities obtained at $20 \mathrm{~min}\left(\mathrm{I}_{20}\right.$ $\min )$ and at baseline $\left(\mathrm{I}_{0 \mathrm{~min}}\right)$ were calculated and represented by the percentage change in intensity from its baseline value, using the following equation: \%Change of $\mathrm{NO}$-associated fluorescent intensity $=\left(I_{20 \min }-I_{0 \min } / I_{0 \text { min }}\right) \times 100$

lated according to the following equation and represented as the percent increase in NO released during the first 20 minutes:

$\%$ changes of $\mathrm{NO}$ - associated fluorescent intensity $=\frac{\left(\mathrm{I}_{20} \mathrm{~min}^{-} \mathrm{I}_{0 \mathrm{~min}}\right) \times 100}{\mathrm{I}_{0} \mathrm{~min}}$

\section{Measurement of metabolic parameters}

At the end of each experiment, the blood sample of each rat was collected to determine the androgen level. Immediately after that, the liver was perfused with ice-cold phosphate buffer saline (PBS) at pH 7.4 and excised. All fat and fibrous tissues on the liver were removed before it was weighed. The liver was kept at $-80^{\circ} \mathrm{C}$ until malondialdehyde (MDA) analyses were done. MDA was performed by using the thiobarbituric acid reaction as described by Ohkawa et al., 1979 [31].

\section{Statistical analyses}

Data are expressed as means \pm SD. For comparison among groups of animals, one-way analysis of variance (one-way ANOVA) and a two-sided alpha level of 0.05 adjusted by 
Tukey's procedure for multiple comparisons were used. $P$ $<0.05$ was considered statistically significant.

\section{Results}

\section{Physiological characteristics}

In Table 1, the results showed that means arterial pressure (MAP) for age-groups (Aged+Veh; $144.68 \pm 5.93 \mathrm{mmHg}$, and Aged+Without-Ex; $144.20 \pm 18.62)$ were significantly higher than the young group (4-6-mo-old; $121.55 \pm 3.43$ $\mathrm{mmHg})(P<0.01)$. However, MAP from both Aged+Gen $(124.58 \pm 2.41 \mathrm{mmHg})$ and Aged+Ex rats $(124.20 \pm 5.31$ $\mathrm{mmHg}$ ) reduced significantly when it was compared to their age- matched control groups $(P<0.05)$. Testosterone levels and the ratios of seminal vesicle/body weights were significantly decreased in Aged+Veh $(0.71 \pm 0.74 \mathrm{ng} / \mathrm{mL}$ and $0.0023 \pm 0.0005)$ and Aged+Without-Ex groups $(0.67$ $\pm 0.77 \mathrm{ng} / \mathrm{mL}$ and $0.0023 \pm 0.0018)$ when compared to the young group $(2.01 \pm 1.31 \mathrm{ng} / \mathrm{mL}$ and $0.0044 \pm$ $0.0008)(P<0.05)$. Genistein supplementation showed no effects on both testosterone level and the ratio of seminal vesicle/body weight. However, in Aged+Ex group, the ratio of seminal vesicle/body weight was significantly higher than the Aged+Without-Ex group $($ Aged $+E x=$ $0.0042 \pm 0.0006$, Aged + Without-Ex $=0.0023+0.0018)(P$ $<0.05)$. This may be due to the effect of exercise training on the fat composition, because there were no significant differences between seminal vesicle weight of the Aged+Ex and Aged+Without-Ex groups.

\section{Levels of liver malondialdehyde}

Indicators of oxidative stress, liver-malondialdehyde (MDA), of Aged+Veh (4.81 $\pm 1.17 \mu \mathrm{mol} / \mathrm{g}$ liver wet weight $)$ and Aged+Without-Ex $(4.33 \pm 2.00 \mu \mathrm{mol} / \mathrm{g}$ liver wet weight) were significantly higher when compared to the young group $(2.42 \pm 0.48 \mu \mathrm{mol} / \mathrm{g}$ liver wet weight) $(P$ $<0.05)$. But the MDA levels of two treated groups, Aged+Gen $(2.53 \pm 0.59 \mu \mathrm{mol} / \mathrm{g}$ liver wet weight $)$ and Aged+Ex ( $2.51 \pm 0.49 \mu \mathrm{mol} / g$ liver wet weight $)$, were significantly lower when compare to their age-matched controls $(P<0.05)$ (Table 1$)$.

\section{Acetylcholine-induced arteriolar response}

As shown in Figure 2, arteriolar dilatation to Ach was significantly impaired in Aged+Veh $(11.07 \pm 2.83 \%)$ when it was compared to the young group $(26.51 \pm 5.60 \%)(P<$ $0.05)$. Interestingly, the dilatory responses of the arterioles to Ach significantly increased in both Aged+Gen (27.41 \pm $8.75 \%)$ and Aged+Ex (31.15 $\pm 4.58 \%)$ groups when compared to their age-matched controls $(P<0.05$ and $P<$ 0.001 , respectively).

\section{Sodium nitroprusside-induced arteriolar response}

To ensure that impairment of arteriolar dilatation to Ach did not interfere with the function of the smooth muscle cells, the vasodilatory response to endothelium-independent vasodilatation was examined by using SNP (10$\left.{ }^{5} \mathrm{M}\right)$. The results showed that there was no significant difference among the young $(25.88 \pm 3.70 \%)$, Aged groups (Aged+Veh, (29.79 $\pm 11.71 \%)$, and Aged+Without-Ex groups $(32.15 \pm 16.56 \%)$ ) (Figure 3$)$.

\section{Direct detection of NO production}

In Figure 4, the NO production was significantly lower in the aged groups (Aged+Veh (35.01 \pm 9.71\%) and Aged+Without-Ex $(38.47 \pm 7.84 \%)$ when compared to the young group $(85.74 \pm 17.99 \%)(P<0.001)$. Interestingly, both Aged+Gen (76.64 $\pm 18.52 \%)$ and Aged+Ex (80.86 \pm $15.62 \%$ ) groups had a significant enhancement of the NO level when compared to their age-matched controls (Aged+Veh and Aged+Without-Ex $)(P<0.05)$. It is noted that genistein and exercise training could enhance NO bioavailability in aging rats.

In Figure 5, linear regression was performed to establish the relationship between the Ach-induced increase in arteriolar diameters and the percent increased in NO-associated fluorescent intensity for the young, Aged+Veh, Aged+Gen, Aged+Without-Ex and Aged+Ex groups. The linear equation obtained was: $\mathrm{y}=0.3567 \mathrm{x}-0.7287, \mathrm{R}^{2}=$ $0.87,(P<0.01)$, where $x$ is the mean of NO-associated fluorescent intensity and $y$ is the mean percentage of diameter change.

Table I: Means \pm SD of physiological and biochemical characteristics of young, aged rats with vehicle (Aged+Veh), genistein (Aged+Gen), without exercise training (Aged+Without-Ex), and exercise training (Aged+Ex).

\begin{tabular}{lccccc}
\hline Group & MAP $(\mathbf{m m H g})$ & $\begin{array}{c}\text { Testosterone } \\
(\mathbf{n g} / \mathbf{m L})\end{array}$ & $\begin{array}{c}\text { Seminal vesicle } \\
\text { weight }(\mathbf{g})\end{array}$ & $\begin{array}{c}\text { Seminal vesicle } \\
\text { weight/body weight }\end{array}$ & $\begin{array}{c}\text { MDA level of liver } \\
(\mu \mathrm{mol} / \mathbf{g} \text { wet wt.) }\end{array}$ \\
\hline Young $(n=5)$ & $121.55 \pm 3.43$ & $2.01 \pm 1.31$ & $2.09 \pm 0.38$ & $0.0044 \pm 0.0008$ & $2.42 \pm 0.48$ \\
Aged+Veh $(n=5)$ & $144.68 \pm 5.93^{* *}$ & $0.71 \pm 0.74^{*}$ & $1.74 \pm 0.33$ & $0.0023 \pm 0.0005^{*}$ & $4.81 \pm 1.17^{*}$ \\
Aged+Gen $(n=5)$ & $124.58 \pm 2.4 I^{*}$ & $1.13 \pm 0.73$ & $2.49 \pm 0.67$ & $0.0036 \pm 0.0008$ & $2.53 \pm 0.59 \#$ \\
$\begin{array}{l}\text { Aged+Without-Ex } \\
(n=5)\end{array}$ & $144.20 \pm 18.62^{* *}$ & $0.67 \pm 0.77^{*}$ & $1.54 \pm 1.31$ & $0.0023 \pm 0.0018^{*}$ & $4.33 \pm 2.00^{*}$ \\
Aged+Ex $(n=5)$ & $124.20 \pm 5.3 I^{\dagger}$ & $0.34 \pm 0.09$ & $2.87 \pm 0.29$ & $0.0042 \pm 0.0006^{\dagger}$ & $2.51 \pm 0.49 \dagger$ \\
\hline
\end{tabular}

$* P<0.05$ compared with young group, ${ }^{* * P}<0.01$ compared with young group, $\# P<0.05$ compared with Aged + Veh group, $\uparrow P<0.05$ compared with Aged+Without-Ex group. 


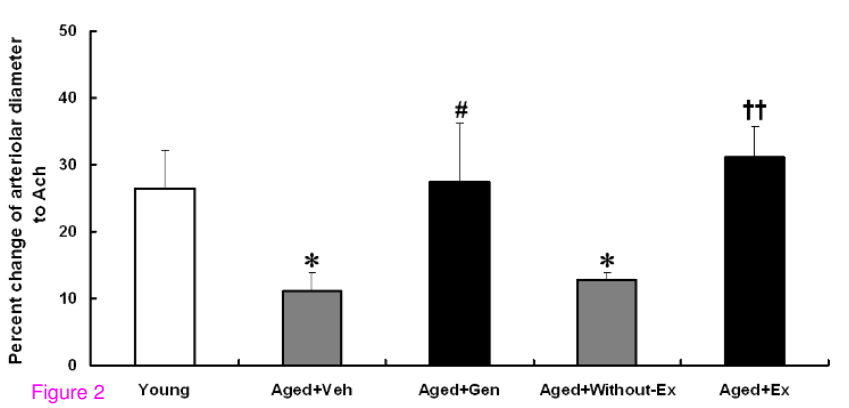

Figure 2

The percentage of increase in arteriolar diameters induced by Ach for young, aged rats with vehicle (Aged+Veh), genistein (Aged+Gen), without exercise training (Aged+Without-Ex), and exercise training (Aged+Ex). $* P<0.05$ compared with young group, $\# P<$ 0.05 compared with Aged+Veh group, t†p $<0.0$ l compared with Aged+Without-Ex group.

\section{Discussion}

In the present study, we have shown that soy phytoestrogen, genistein, and 8-week exercise training could reduce the age-induced cardiovascular abnormalities, such as hypertension and age-induced endothelial dysfunction. These treatments can increase NO bioavailability to have a linear correlation with endothelial-dependent vasodilatation improvement.

Since it is well known that age-induced oxidative stress can cause abnormal vascular functions by enhancing resistance to blood flow, hence, in this study, we measured the MDA levels in liver of the rats from the agegroups. The condition of the age-induced oxidative stress was indicated by an elevated MDA level which can con-

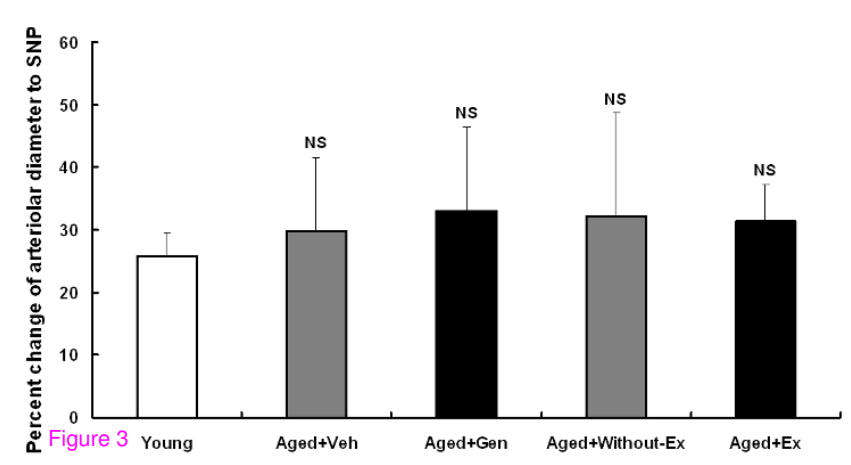

Figure 3

The percentage change of arteriolar diameters induced by SNP for young, aged rats with vehicle (Aged+Veh), genistein (Aged+Gen), without exercise (Aged+Without-Ex) and exercise (Aged+Ex). No significantly difference as compared to young group. No significantly difference as compared to Aged groups.

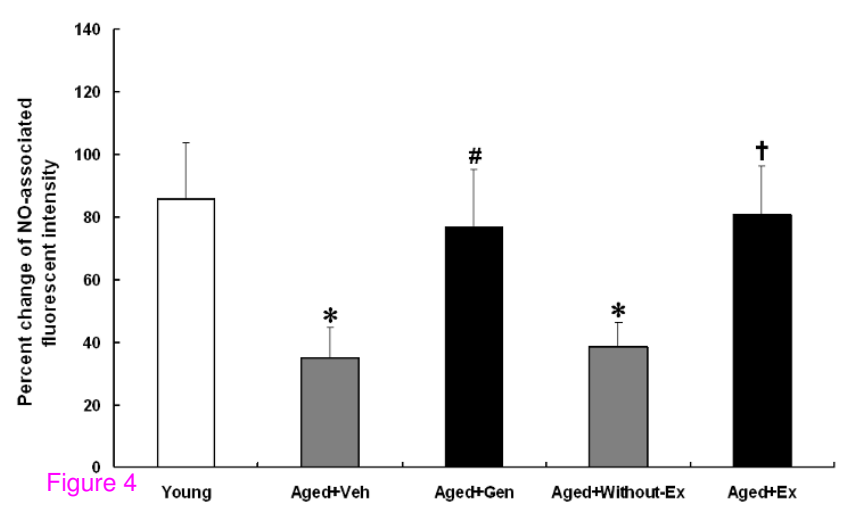

Figure 4

The percentage change of NO-associated fluorescent intensity for young, aged rats with vehicle (Aged+Veh), genistein (Aged+Gen), without exercise (Aged+Without-Ex) and exercise (Aged+Ex). $* P<$

0.05 compared with young group, $\# P<0.05$ compared with Aged+Veh group, $\uparrow P<0.05$ compared with Aged+WithoutEx group.

tribute to the sequential process, age-induced endothelial dysfunction $[8,8]$. In the report of Taddei et al. [9], it has been confirmed that the response to acetylcholine declined with age. Moreover, it has been suggested that the phenomenon of age-induced endothelial dysfunction is widespread and applies to the whole circulation [32]. For that reason, it is possible to increase the total peripheral vascular resistance and MAP in the aged group.

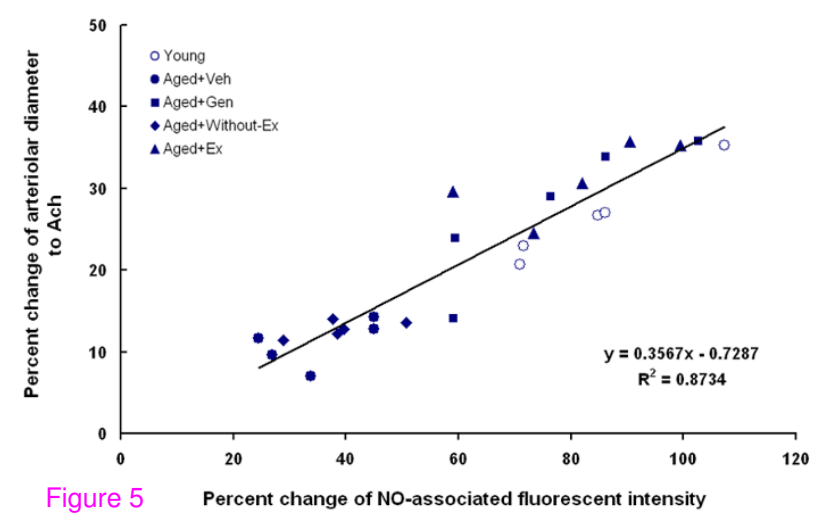

Figure 5

The correlations between percent changes of NOassociated fluorescent intensity and the percent arteriolar diameter changes were examined by using Pearson's Correlation and the best-fitting linear regression. All data were taken from values of each groups: young, aged+vehicle (Aged+Veh), aged+genistein (Aged+Gen), aged+without exercise (Aged+Without-Ex) and aged+exercise (Aged+Ex). (Pearson's correlation $=0.87$, $P<0.01)$. 
The results from the MDA levels showed that long-term treatment of genistein can scavenge the age-induced excess free radicals, especially superoxide anions which can directly damage molecules of protein, lipid, and DNA as which leads to cell dysfunction. Our observation of increased Ach-induced vasodilatation in Aged+Gen group confirms that anti-oxidant agent can prevent age-induced endothelial dysfunction. This ability may enhance endothelial-dependent vasodilatation by protecting NO from direct interaction with the superoxide radical. Since NO bioavailability is associated with endotheliumdependent vasodilatation, the greater NO bioavailability level, therefore, a more pronounced endotheliumdependent vasodilatation effect will be observed.

Furthermore, many investigators are interested in genistein's mechanism and how it is able to increase NO bioavailability $[21,21]$. For example, Walker et al. showed that genistein, 17ß-estradiol, can produce acute NO-dependent vasodilatation which may affect endothelial nitric oxide synthase (eNOS) activity [22]. On the other hand, it has been shown that genistein has a similar affinity as estrogen because of the novel ER- $\beta$ present in the vasculature [21]. The ER- $\beta$ in endothelial cell has been shown to stimulate NO-production also known as the non-genomic effect of estrogen [33]. Interestingly, it has been shown that acute topical application of genistein mediated vasodilatation via prostacyclin $\left(\mathrm{PGI}_{2}\right)$ and $\mathrm{NO}$ productions [34].

Yet, other investigations indicated that an acute action of genistein-induced endothelial NO production was mediated by another pathway of protein kinase A (PKA) which is unrelated to the estrogenic effect [35]. They also suggested that this pathway may be crucial in protecting the cardiovascular effects seen in soy phytoestrogens. For example, Liu et al. (2004) [35] demonstrated that 1- $\mu \mathrm{M}$ genistein could directly activate eNOS in intact bovine aortic endothelial cells and endothelial cells from human umbilical vein over an incubation period of 10 minutes. They also proposed that these effects were mediated by PKA and were unrelated to the estrogenic effect. In another report, Si et al. (2008) showed that genistein had a direct genomic effect on the vascular wall causing an increased eNOS expression and NO synthesis in spontaneously hypertensive rat model [36].

Our result (Table 1) confirmed that both testosterone levels and ratios of seminal weights were significantly decreased by aging. Genistein supplementation and exercise training did not affect those parameters. Other studies have reported similar findings that low doses of phytoestrogens do not have any effects on reproductive functions of either males or females [37,37]. However, the increased seminal vesicle/body weight ratio in Aged+Ex group may have been from the metabolic effect of exercise training on fat composition leading to weight loss in this group.

Aside from that, our findings indicated that genistein and exercise training could protect endothelial functions from age-induced dysfunction. A significant reduction in MDA levels in Aged+Ex group was observed when compared to the Aged+Without-Ex group (Table 1). These results confirmed the effectiveness of our training protocol, $40 \mathrm{~min} /$ day, 5 day/week for a total of 8 weeks, in reducing peripheral vascular resistance in aged male rat. The following might help explain the benefits of long-term exercise training: 1) reduction of age-induced oxidative stress by increasing the enzymatic anti-oxidants expression, and 2) an increase in shear-stress mediated eNOS activity [39]. Also Ahmadiasl and colleagues (2007) showed that longterm endurance training could increase superoxide dismutase (SOD) activities in rat myocardium [40]. There are several approaches that may explain how exercise training can enhance endothelial function, yet the effects of endurance exercise training on the oxidative status and antioxidant defense system remain unclear. Discrepancies are due to different training protocols used and, therefore, caution is warranted in interpreting these results.

Nevertheless, in our study, a moderate exercise training program consisting of 8 weeks is sufficient enough to reduce age-induced endothelium dysfunction. It appears to us that exercise training has the same effects as seen in genistein because of its ability to protect NO bioavailability in the Aged group and enhance endothelium-dependent vasodilatation. The reason for this may be that exercise training improves endothelial function and provides cardioprotective benefits.

Additional analysis using an in vitro study, Kashiwagi et al. (2002) showed a linear relationship between the gray levels of fluorescence intensities and DAF-2T concentrations (between $10 \mathrm{nmol} / \mathrm{L}$ and $1 \mu \mathrm{mol} / \mathrm{L}$ ) [27]. For this reason, we chose to further investigate whether there are any correlation between $\mathrm{NO}$-associated fluorescent intensity and the Ach-evoked vasodilatation in all five groups. Our correlation results between the means percent changes of NO-associated fluorescent intensity and the mean percent of arteriolar diameter changes from all 5 groups were significantly correlated and are shown in Figure 5 (Pearson's correlation $=0.87, P<0.01$ ). These findings suggested that Ach-induced arteriolar dilatation could be restored by using genistein and exercise training to increase intraendothelial NO bioavailability.

The results obtained showed an increase of NO bioavailability after utilizing two interventions. Both of these interventions have multiple functions effecting eNOS 
expression, eNOS activity, and eNOS cofactor; tetrahydrobiopterin $\left(\mathrm{BH}_{4}\right)$.

Both interventions can increase eNOS expression through both direct and indirect pathways [35,36,41,42]. Similarly, Tanabe and his colleagues (2003) reported that the 8 -week exercise swimming could up-regulate eNOS expression in the aorta in aged rats [41]. Along the same lines, Sindler et al. (2009) suggested that exercise training can restore the important eNOS cofactor, tetrahydrobiopterin $\left(\mathrm{BH}_{4}\right)$, content and then leads to enhance flowstimulated NO availability in old rats [42].

Our findings parallel previous research showing NO bioavailability enhances endothelium-dependent vasodilatation. Our results may be the first in vivo evidence of genistein and exercise training in protecting endothelial cells against age-induced oxidative stress by using a fluorescent indicator-diaminofluorescein (DAFs). The in situ release of NO from cremasteric endothelial cells after acetylcholine activation was examined in both genistein and exercise training groups. The effect of genistein and exercise training on increased NO bioavailability may be associated with multiple direct and indirect pathways and additional studies are needed to confirm these results.

\section{Conclusion}

The findings indicated that long-term genistein treatment and exercise training could improve age-induced endothelial dysfunction in cremasters and increase NO bioavailability in aging male rats.

\section{Competing interests}

The authors declare that they have no competing interests.

\section{Authors' contributions}

$\mathrm{SE}$ assisted the co-authors in the design of study. The experiments were carried out by SE. SP, PS and DS supervised the experiments, interpreted and analyzed the data. SE prepared the initial draft of the manuscript and SP mindfully read and revised the manuscript. All authors have read and approved the manuscript.

\section{Acknowledgements}

This study was supported by Ratchadaphiseksomphot Fund, Faculty of Medicine, the $90^{\text {th }}$ Anniversary of Chulalongkorn University Fund, Graduate School, Chulalongkorn University, and National Research Council of Thailand (GRB_14_50_30_12).

\section{References}

I. Egashira K, Inou T, Hirooka Y, Kai H, Sugimachi M, Suzuki S, Kuga T, Urabe $Y$, Takeshita A: Effects of age on endothelium-dependent vasodilation of resistance coronary artery by acetylcholine in humans. Circulation 1993, 88:77-8I.

2. Taddei S, Galetta F, Virdis A, Ghiadoni L, Salvetti G, Franzoni F, Giusti $C$, Salvetti A: Physical activity prevents age-related impairment in nitric oxide availability in elderly athletes. Circulation 2000, I 1 I:2896-2901.
3. Al-Shaer MH, Choueiri NE, Correia ML, Sinkey CA, Barenz TA, Haynes WG: Effects of aging and atherosclerosis on endothelial and vascular smooth muscle function in humans. Int $\mathrm{J}$ Cardiol 2006, I09:20I-206.

4. Singh N, Prasad S, Singer DR, MacAllister RJ: Ageing is associated with impairment of nitric oxide and prostanoid dilator pathways in the human forearm. Clin Sci (Lond) 2002, 102:595-600.

5. Csiszar A, Ungvari Z, Edwards JG, Kaminski P, Wolin MS, Koller A, Kaley G: Aging-induced phenotypic changes and oxidative stress impair coronary arteriolar function. Circ Res 2002, 90: II59-1166.

6. Hamilton CA, Brosnan MJ, Mclntyre M, Graham D, Dominiczak AF: Superoxide excess in hypertension and aging: a common cause of endothelial dysfunction. Hypertension 200I, 37:529-534.

7. Harrison DG: Cellular and molecular mechanisms of endothelial cell dysfunction. J Clin Invest 1997, 100:2153-2157.

8. Roberts LJ 2nd, Reckelhoff JF: Measurement of F(2)-isoprostanes unveils profound oxidative stress in aged rats. Biochem Biophys Res Commun 200I, 287:254-256.

9. Taddei S, Virdis A, Ghiadoni L, Salvetti G, Bernini G, Magagna A, Salvetti $A$ : Age-related reduction of NO availability and oxidative stress in humans. Hypertension 200I, 38:274-279.

10. Loo B van der, Labugger R, Skepper JN, Bachschmid M, Kilo J, Powell JM, Palacios-Callender M, Erusalimsky JD, Quaschning T, Malinski T, Gygi D, Ullrich V, Luscher TF: Enhanced peroxynitrite formation is associated with vascular aging. J Exp Med 2000, 192:173I-1744.

II. Gryglewski RJ, Palmer RM, Moncada S: Superoxide anion is involved in the breakdown of endothelium-derived vascular relaxing factor. Nature 1986, 320:454-456.

12. Adlercreutz H, Markkanen $\mathrm{H}$, Watanabe S: Plasma concentrations of phyto-oestrogens in Japanese men. Lancet 1993, 342:1209-1210.

13. Barnes S: Evolution of the health benefits of soy isoflavones. Proc Soc Exp Biol Med 1998, 217:386-392.

14. Keys A: Coronary heart disease in seven countries. Circulation 1970, 4 I (suppI I):II-2II.

15. Honore EK, Williams JK, Anthony MS, Clarkson TB: Soy isoflavones enhance coronary vascular reactivity in atherosclerotic female macaques. Fertil Steril 1997, 67:148-154.

16. Lissin LW, Cooke JP: Phytoestrogens and cardiovascular health. J Am Coll Cardiol 2000, 35:1403-1410.

17. Tikkanen MJ, Wahala K, Ojala S, Vihma V, Adlercreutz H: Effect of soybean phytoestrogen intake on low density lipoprotein oxidation resistance. Proc Natl Acad Sci USA 1998, 95:3 I06-3II0.

18. Chanawirat A, Khemapech S, Patumraj S, Siriviriyakul P: Genistein replacement therapy on endothelial dysfunction and bone loss in bilateral ovariectomized rats. Clin Hemorheol Microcirc 2006, 34:309-3I4.

19. Khemapech S, Monsiri K, Patumraj S, Siriviriyakul P: Genistein replacement therapy for vasodilation disorder in bilateral ovariectomized rats. Clin Hemorheol Microcirc 2003, 29:27I-277.

20. Molsiri K, Khemapech S, Patumraj S, Siriviriyakul P: Preventive mechanism of genistein on coronary endothelial dysfunction in ovariectomized rats: an isolated arrested heart model. Clin Hemorheol Microcirc 2004, 31:59-66.

21. Squadrito F, Altavilla D, Squadrito G, Saitta A, Cucinotta D, Minutoli L, Deodato B, Ferlito M, Campo GM, Bova A, Caputi AP: Genistein supplementation and estrogen replacement therapy improve endothelial dysfunction induced by ovariectomy in rats. Cardiovasc Res 2000, 45:454-462.

22. Walker HA, Dean TS, Sanders TA, Jackson G, Ritter JM, Chowienczyk $\mathrm{PJ}$ : The phytoestrogen genistein produces acute nitric oxidedependent dilation of human forearm vasculature with similar potency to I 7beta-estradiol. Circulation 200I, 1 03:258-262.

23. DeSouza CA, Shapiro LF, Clevenger CM, Dinenno FA, Monahan KD, Tanaka H, Seals DR: Regular aerobic exercise prevents and restores age-related declines in endothelium-dependent vasodilation in healthy men. Circulation 2000, 102:135 I-1 357.

24. Ogawa T, Spina RJ, Martin WH 3rd, Kohrt WM, Schechtman KB, Holloszy JO, Ehsani AA: Effects of aging, sex, and physical training on cardiovascular responses to exercise. Circulation 1992, 86:494-503.

25. Leosco D, laccarino G, Cipolletta E, De Santis D, Pisani E, Trimarco V, Ferrara N, Abete P, Sorriento D, Rengo F, Trimarco B: Exercise 
restores beta-adrenergic vasorelaxation in aged rat carotid arteries. Am J Physiol Heart Circ Physiol 2003, 285:H369-374.

26. Gavins FN, Chatterjee BE: Intravital microscopy for the study of mouse microcirculation in anti-inflammatory drug research: focus on the mesentery and cremaster preparations. J Pharmacol Toxicol Methods 2004, 49: I-I4.

27. Kashiwagi S, Kajimura M, Yoshimura Y, Suematsu M: Nonendothelial source of nitric oxide in arterioles but not in venules: alternative source revealed in vivo by diaminofluorescein microfluorography. Circ Res 2002, 91:e55-64.

28. Sridulyakul P, Wongeak-in N, Patumraj S: Increased nitric oxide level in diabetic rats from vitamin $\mathrm{C}$ supplementation: an in vivo detection using diaminofluorescein. Asian Biomed 2008, 2:37I-337.

29. Kojima H, Nakatsubo N, Kikuchi K, Kawahara S, Kirino Y, Nagoshi $\mathrm{H}$, Hirata $Y$, Nagano T: Detection and imaging of nitric oxide with novel fluorescent indicators: diaminofluoresceins. Anal Chem 1998, 70:2446-2453.

30. Matsubara M, Yao K, Hasegawa K: Benidipine, a dihydropyridinecalcium channel blocker, inhibits lysophosphatidylcholineinduced endothelial injury via stimulation of nitric oxide release. Pharmacol Res 2006, 53:35-43.

31. Ohkawa $\mathrm{H}$, Ohishi N, Yagi K. Assay for lipid peroxides in animal tissues by thiobarbituric acid reaction. Anal Biochem 1979, 95:35I-358.

32. Taddei $S$, Virdis A, Mattei P, Ghiadoni L, Gennari A, Fasolo CB, Sudano I, Salvetti A: Aging and endothelial function in normotensive subjects and patients with essential hypertension. Circulation 1995, 91:1981-1987.

33. Guo X, Razandi M, Pedram A, Kassab G, Levin ER: Estrogen induces vascular wall dilation: mediation through kinase signaling to nitric oxide and estrogen receptors alpha and beta. J Biol Chem 2005, 280:19704-19710.

34. Siriviriyakul $P$, Khemapech $S$, Monsiri K, Patumraj S: The vascular effect of genistein: what is its mechanism, nitric oxide or PGI2? Clin Hemorheol Microcirc 2006, 34:97-I0I.

35. Liu D, Homan LL, Dillon JS: Genistein acutely stimulates nitric oxide synthesis in vascular endothelial cells by a cyclic adenosine 5'-monophosphate-dependent mechanism. Endocrinology 2004, I 45:5532-5539.

36. Si H, Liu D: Genistein, a soy phytoestrogen, upregulates the expression of human endothelial nitric oxide synthase and lowers blood pressure in spontaneously hypertensive rats. $J$ Nutr 2008, 138:297-304.

37. Anthony MS, Clarkson TB, Hughes CL Jr, Morgan TM, Burke GL: Soybean isoflavones improve cardiovascular risk factors without affecting the reproductive system of peripubertal rhesus monkeys. J Nutr 1996, I 26:43-50.

38. Mitchell JH, Cawood E, Kinniburgh D, Provan A, Collins AR, Irvine DS: Effect of a phytoestrogen food supplement on reproductive health in normal males. Clin Sci (Lond) 200I, 100:613-618.

39. Maiorana A, O'Driscoll G, Taylor R, Green D: Exercise and the nitric oxide vasodilator system. Sports Med 2003, 33:1013-1035.

40. Ahmadias N, Soufi FG, Alipour M, Bonyadi M, Sheikhzadeh F, Vatankhah A, Salehi I, Mesgari M: Effects of age increment and 36-week exercise training on antioxidant enzymes and apoptosis in rat heart tissue. J Sport Sci Med 2007, 6:243-249.

41. Tanabe T, Maeda S, Miyauchi T, lemitsu M, Takanashi M, IrukayamaTomobe $Y$, Yokota T, Ohmori H, Matsuda M: Exercise training improves ageing-induced decrease in eNOS expression of the aorta. Acta Physiol Scand 2003, I 78:3-10.

42. Sindler AL, Delp MD, Reyes R, Wu G, Muller-Delp JM: Effects of ageing and exercise training on eNOS uncoupling in skeletal muscle resistance arterioles. J Physiol 2009, 587:3885-3897.

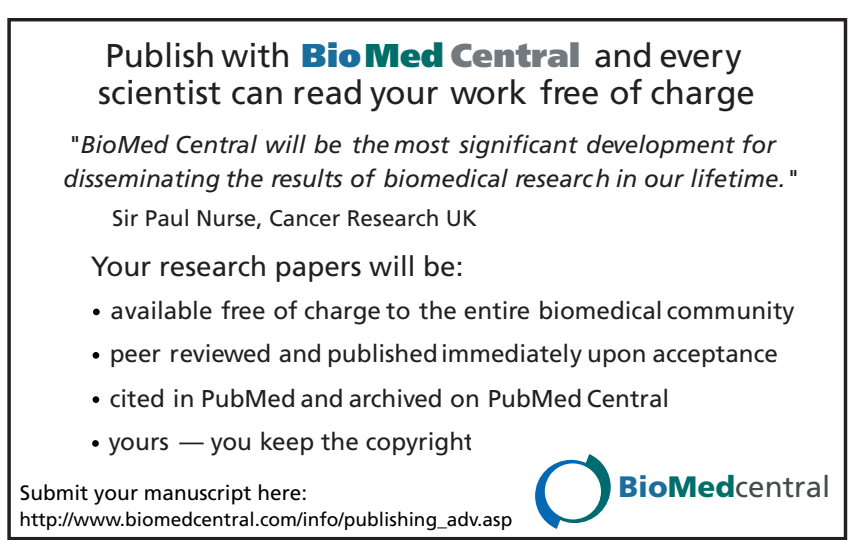

